\title{
Neuropsychopharmacology Reviews: The Next Generation of Progress
}

T his volume represents the inaugural issue of Neuropsychopharmacology Reviews. As an annual publication, the offering is designed to provide authoritative and timely coverage of contemporary topics in the field. As subscribers to Neuropsychopharmacology, members of the College have early access to these reports both on line and in print.

Neuropsychopharmacology Reviews replaces the Generation of Progress, which consisted of five volumes published intermittently between 1968 and 2002. While the Generation of Progress served for decades as a major reference work, a single large volume is an increasingly difficult mechanism for promulgating new data given the pace of research, developments in information technology, and the time needed for authoring, editing, printing, and distributing such a massive work. After considering several alternatives, it was decided that a yearly publication of review articles is more easily managed, and makes possible more timely coverage of critical topics than is possible with a major reference work. Timely because the reviews are written shortly before the publication, and topical in that it will be possible to publish updates and perspectives on the same subject as often as warranted. To help ensure timeliness, the work includes a Hot Topics chapter that is prepared just prior to the production deadline. This section contains summaries of some of the most recent developments in the field. The volume also features downloadable graphics that can be used as a teaching resource. It is anticipated that the regular publication of this high-quality review journal will build a recognizable franchise, further establishing the College as the most authoritative source for information in the discipline.

While the primary audience for this offering is clinical investigators and neuroscientists, authors are encouraged to prepare reports that are informative for practicing physicians and the lay public as well. Although the aim is to provide coverage of all aspects of clinical and basic neuropsychopharmacology every five years or so, no limits are placed on how often a particular subject may be reviewed since selection of material is driven by developments in the field.

Preparation of Neuropsychopharmacology Reviews is overseen by members of the College, two of whom serve as Series Editors. The editors are assisted by an Editorial Board comprised of individuals who will serve as Volume Editors on subsequent editions of the work. The College is fortunate in having Husseini Manji and Peter Kalivas as the initial Series Editors. Production and publication is handled by the Nature Publishing Group.

The College is indebted to many individuals for the timely production of this first issue of Neuropsychopharmaclogy Reviews. Besides Drs Manji and Kalivas, others deserving special recognition are Ronnie Wilkins and his associates in the ACNP office, in particular Jennifer Mahar and Diane Drexler, and to Joyce-Rachel John and Elizabeth Durzy with the Nature Publishing Group. Thanks to their extraordinary efforts, less than a year elapsed between recruitment of the Series Editors and receipt of the final manuscript for this volume. During this interval the theme was selected, authors recruited, and the manuscripts written, peer reviewed and revised. Thus, as intended, this offering is timely and current.

Neuropsychopharmacology Reviews will serve not only as an information source, but also as a showcase for work performed by ACNP members and as a stimulus for research in the field. To these ends, readers are encouraged to recommend topics for consideration by the Editorial Board. Please do not hesitate to communicate directly with Drs Manji or Kalivas. We look forward to your comments and trust you will enjoy and benefit from this latest offering from the College.

Sam J Enna, PhD

Chair, ACNP Publications Committee The University of Kansas, School of Medicine, Kansas City, KS, USA 